Article

\title{
Carfilzomib Based Treatment Strategies in the Management of Relapsed/Refractory Multiple Myeloma with Extramedullary Disease
}

\author{
Xiang Zhou ${ }^{1, *}$, Patricia Flüchter ${ }^{1}$, Katharina Nickel ${ }^{1}$, Katharina Meckel ${ }^{1}$, Janin Messerschmidt ${ }^{1}$, \\ David Böckle ${ }^{1}$, Sebastian Knorz ${ }^{1}$, Maximilian Johannes Steinhardt ${ }^{1}$ D , Franziska Krummenast ${ }^{1}$, \\ Sophia Danhof ${ }^{1}$, Hermann Einsele ${ }^{1}$, K. Martin Kortüm ${ }^{1}$ (D) and Leo Rasche 1,2,* \\ 1 Department of Internal Medicine II, University Hospital of Würzburg, D-97080 Würzburg, Germany \\ 2 Mildred Scheel Early Career Center, University Hospital of Würzburg, D-97080 Würzburg, Germany \\ * Correspondence: Zhou_x@ukw.de (X.Z.); Rasche_1@ukw.de (L.R.)
}

Received: 13 March 2020; Accepted: 20 April 2020; Published: 23 April 2020

check for updates

\begin{abstract}
Published experience with carfilzomib in patients with relapsed/refractory multiple myeloma (RRMM) and extramedullary disease (EMD) is still limited. The current study aimed to assess the efficacy and safety of carfilzomib containing therapy regimens in EMD. We retrospectively analyzed 45 patients with extramedullary RRMM treated with carfilzomib from June 2013 to September 2019. The median age at the start of carfilzomib was 64 (range 40-80) years. Twenty (44\%) and 25 (56\%) patients had paraosseous manifestation and EMD without adjacency to bone, respectively. The serological overall response rate (ORR) was 59\%. Extramedullary response was evaluable in 33 patients, nine (27\%) of them achieved partial remission (PR) (ORR = 27\%). In $15(33 \%)$ patients, we observed no extramedullary response despite serological response. The median progression-free survival (PFS) and overall survival (OS) were five (95\% CI, 3.5-6.5) and ten (95\% CI, 7.5-12.5) months, respectively. EMD without adjacency to bone was associated with a significantly inferior PFS ( $p=0.004)$ and OS ( $p=0.04)$ compared to paraosseous lesions. Carfilzomib based treatment strategies showed some efficacy in heavily pretreated patients with extramedullary RRMM but could not overcome the negative prognostic value of EMD. Due to the discrepancy between serological and extramedullary response, evaluation of extramedullary response using imaging is mandatory in these patients.
\end{abstract}

Keywords: carfilzomib; extramedullary disease; multiple myeloma; relapse; refractory

\section{Introduction}

In multiple myeloma (MM), tumor growth is usually strongly dependent on the bone marrow microenvironment [1]. However, extramedullary disease (EMD) has been reported to occur in 6\%-37\% of $\mathrm{MM}$ patients, and the frequency increases during the course of the disease. The incidence can be as high as $70 \%$ in autopsy studies [2-4]. In addition, the pathogenesis of EMD remains largely unclear. Upregulation of angiogenesis and adhesion related genes might be a mechanism in EMD development [5]. C-X-C-motif chemokine receptor 4 (CXCR4) expression and hypoxia have also been reported to play a potential role in EMD growth [6,7]. Moreover, high-risk cytogenetics are significantly enriched in MM with EMD [8-12], and studies consistently showed EMD to be associated with poor outcome [12-16]. To date, there is no established approach for treatment of relapsed/refractory multiple myeloma (RRMM) with EMD.

Earlier, we and others reported on intensive multi-agent therapies, such as VDT-PACE (bortezomib, dexamethasone, thalidomide, cisplatin, doxorubicin, cyclophosphamide, and etoposide) 
and Dexa-BEAM (dexamethasone, carmustine, etoposide, cytarabine, and melphalan), which have shown some efficacy $[17,18]$. Furthermore, allogeneic stem cell transplantation has been reported to be an option for EMD [19]. In the phase 2 SIRIUS trial, the overall response rate (ORR) of daratumumab monotherapy was only $21.4 \%$ (3/14) in patients with EMD vs. $30.4 \%(28 / 92)$ of patients without EMD [20]. Notably, none of the above-mentioned strategies led to long-term disease-free survival. Therefore, identifying novel treatment strategies for patients suffering from EMD still represents an urgent medical need. Unfortunately, patients with extramedullary RRMM have only limited access to treatments within clinical trials due to the common exclusion criteria, such as non-secretory disease, central nervous system (CNS) involvement, and poor performance status.

Carfilzomib is a new generation proteasome inhibitor (PI), which in contrast to bortezomib, irreversibly binds to the 20S subunit of the proteasome and has been approved by the US Food and Drug Administration (FDA) for the treatment of RRMM [21]. In the phase 3 ENDEAVOR trial, superior efficacy of carfilzomib compared to bortezomib was observed in patients with RRMM [22], and patients with high-risk cytogenetics benefited from the replacement of bortezomib with carfilzomib [23]. Moreover, the combination of carfilzomib with immunomodulatory drugs (IMiD) lenalidomide and pomalidomide or the monoclonal antibody daratumumab is highly effective in RRMM [24-26]. However, published experience with carfilzomib in patients with extramedullary RRMM is still limited. The current study aimed to analyze carfilzomib containing therapy regimens in EMD.

\section{Methods}

\subsection{Patients}

We performed a single-center retrospective analysis. Utilizing our electronic database, we identified patients with extramedullary RRMM treated with carfilzomib-based regimens from June 2013 to September 2019 at our institution. RRMM was defined according to the current consensus recommendations [27]. EMD included paraosseous lesions originating from bone and extramedullary plasmocytomas without direct bone contact. The diagnosis of EMD was based on the histology of tumor bulk or, if biopsy was not possible, on imaging using computed tomography (CT), diffusion weighted magnetic resonance imaging (MRI), or positron emission tomography (PET). We did not include plasma cell leukemia in this analysis. Patients with at least one of the following aberrations were considered as high-risk cytogenetics: del(17p), $\mathrm{t}(4 ; 14), \mathrm{t}(14 ; 16)$, and $\mathrm{t}(14 ; 20)$ [28-30]. We retrieved and investigated patients' demographic characteristics at diagnosis of MM and at the start of carfilzomib-containing treatment, MM related data (time point of diagnosis, subtype, cytogenetics, prior therapy lines, response and survival outcome), EMD related data (localization, adjacency to bones and secretory activity), treatment and adverse events (AEs) during therapy.

\subsection{Treatment, Response, and Outcome}

Carfilzomib was given on day 1, 2, 8, 9, 15, and 16 as intravenous (IV) short infusion in a 28-day cycle. We started carfilzomib at a dose of $20 \mathrm{mg} / \mathrm{m}^{2}$ on day 1 and 2 of the first cycle, and the dose was increased to $27 \mathrm{mg} / \mathrm{m}^{2}$ on day 8 if tolerated. Doses of carfilzomib were escalated or reduced according to the treating physician's discretion. In our study, carfilzomib was administered in combination with at least one additional drug, including dexamethasone, IMiD, alkylating agent, and monoclonal antibody, i.e., daratumumab and elotuzumab.

We analyzed ORR, clinical benefit rate (CBR), overall survival (OS) and progression-free survival (PFS) following the current criteria of the International Myeloma Working Group (IMWG) [31,32]. Adverse events (AE) during carfilzomib containing treatment were characterized according to the Common Terminology Criteria for Adverse Events (CTCAE) Version 4.0. 


\subsection{Statistical Analysis}

Using descriptive statistics, we summarized patients' characteristics as absolute number and percentage, and if not otherwise stated as median and range. The survival analysis was performed with Kaplan-Meier method, and log-rank test was used to compare the survival outcome between subgroups. We used Fisher's exact test to evaluate the difference in response rate (ORR and CBR) between the subgroups. These analyses were performed with GraphPad Prism 5.0. A $p$-value less than 0.05 was considered as statistically significant.

\section{Results}

\subsection{Patients' Characteristics}

In total, we identified 45 patients with extramedullary RRMM that were treated with carfilzomib containing regimens. The majority of the patients $(n=33,73 \%)$ were male, and the median age at the start of carfilzomib for EMD was 64 (range 40-80) years. At the initial diagnosis of MM, primary EMD with and without adjacency to bone was already present in $16(35 \%)$ and $1(2 \%)$ patients, respectively. At presentation, 22 patients (49\%) had high-risk cytogenetics from bone marrow biopsy. At start of carfilzomib as salvage therapy for secondary EMD, 20 (44\%) and $25(56 \%)$ patients suffered from EMD with and without adjacency to bone, respectively. Monoclonal protein in serum was detectable in the majority of the patients $(n=42,93 \%)$. Muscle, skin, and soft tissue manifestation was the most frequent EMD presentation in our cohort $(n=38,84 \%)$. Spinal cord and paravertebral lesions were seen in 25 patients (56\%). Twenty (44\%), $13(29 \%), 11(24 \%)$, and $2(4 \%)$ patients had lymph node manifestation, malignant pleural effusion, parenchymal organ involvement, and gastrointestinal tract lesions, respectively. Lactate dehydrogenase (LDH) was elevated in $22(49 \%)$ patients at start of carfilzomib for EMD.

In our cohort, patients had been treated with a median of four (range 1-9) prior lines of therapy. Forty-three (96\%) patients were exposed to bortezomib, and eight $(18 \%)$ patients had received carfilzomib prior to secondary EMD. Lenalidomide, pomalidomide, and thalidomide had been given in $35(78 \%), 22(49 \%)$, and $10(22 \%)$ patients, respectively. Eighteen (40\%) and three (7\%) were treated with monoclonal antibodies daratumumab and elotuzumab, respectively. Forty-four (98\%) and seven (15\%) patients underwent autologous and allogeneic stem cell transplant (SCT), respectively. Seventy-three percent of the patients $(n=33)$ were refractory to the last line of therapy. Patients' characteristics are summarized in Table 1.

\subsection{Treatment and Response to Therapy}

Overall, carfilzomib was administered twice weekly, and patients received a median of three (range 1-18) cycles of carfilzomib. The maximal dose of carfilzomib ranged from 15 to $56 \mathrm{mg} / \mathrm{m}^{2}$, and the majority of patients $\left(n=25,56 \%\right.$ ) received a maximal carfilzomib dose of $27 \mathrm{mg} / \mathrm{m}^{2}$ twice weekly. All the patients were treated with dexamethasone $20-40 \mathrm{mg}$ qw. The treatment regimens are summarized in Table 2. Regimens and doses were modified according to the treating physician's choice. 
Table 1. Patients' characteristics.

\begin{tabular}{|c|c|}
\hline Patients, $n$ & 45 \\
\hline \multicolumn{2}{|l|}{ Gender, $n(\%)$} \\
\hline Male & $33(73)$ \\
\hline Female & $12(27)$ \\
\hline \multicolumn{2}{|l|}{ Subtype, $n(\%)$} \\
\hline $\mathrm{IgG}$ & $26(58)$ \\
\hline $\operatorname{Ig} A$ & $14(31)$ \\
\hline $\mathrm{LC}$ & $5(11)$ \\
\hline \multicolumn{2}{|l|}{ ISS Stage, $n(\%)$} \\
\hline I & $22(49)$ \\
\hline II & $6(13)$ \\
\hline III & $8(18)$ \\
\hline NA & $9(20)$ \\
\hline \multicolumn{2}{|l|}{ Cytogenetics, $n(\%)$} \\
\hline High-risk & $22(49)$ \\
\hline Standard-risk & $18(40)$ \\
\hline NA & $5(11)$ \\
\hline Age at Start of Carfilzomib due to EMD Relapse, Median, Years (Range) & $64(40-80)$ \\
\hline \multicolumn{2}{|l|}{ Bone Marrow Involvement at Start of Carfilzomib due to EMD Relapse } \\
\hline Yes & $21(47)$ \\
\hline No & $4(9)$ \\
\hline NA & $20(44)$ \\
\hline \multicolumn{2}{|l|}{ Serological MM Activity at Start of Carfilzomib due to EMD Relapse, $n(\%)$} \\
\hline With Secretory Activity & $42(93)$ \\
\hline Non-Secretory & $3(7)$ \\
\hline \multicolumn{2}{|l|}{ Serum LDH at Start of Carfilzomib due to EMD Relapse, $n(\%)$} \\
\hline Elevated & $22(49)$ \\
\hline Normal & $23(51)$ \\
\hline \multicolumn{2}{|l|}{ Prior Lines of Therapy, $n(\%)$} \\
\hline $1-2$ & $15(33)$ \\
\hline $3-5$ & $16(36)$ \\
\hline$\geq 6$ & $14(31)$ \\
\hline \multicolumn{2}{|l|}{ Response Status to The Last Therapy Line, $n(\%)$} \\
\hline Refractory to The Last Line of Therapy & $33(73)$ \\
\hline Progression from Remission & $12(27)$ \\
\hline \multicolumn{2}{|l|}{ Characteristics of EMD at Start of Carfilzomib, $n(\%)$} \\
\hline EMD Adjacent to Bone & $20(44)$ \\
\hline EMD without Adjacency to Bone & $25(56)$ \\
\hline \multicolumn{2}{|l|}{ Presentation/Localization of EMD, $n(\%)$} \\
\hline Muscle, Skin, and Soft Tissue & $38(84)$ \\
\hline Spinal Cord and Paravertebral Lesion & $25(56)$ \\
\hline Lymph Node & $20(44)$ \\
\hline Pleural Effusion & $13(29)$ \\
\hline Parenchymal Organ & $11(24)$ \\
\hline Gastrointestinal Tract & $2(4)$ \\
\hline \multicolumn{2}{|l|}{ Prior Treatment, $n(\%)$} \\
\hline \multicolumn{2}{|l|}{ PIs } \\
\hline Bortezomib & $43(96)$ \\
\hline Carfilzomib & $8(18)$ \\
\hline \multicolumn{2}{|l|}{ IMiDs } \\
\hline Lenalidomide & $35(78)$ \\
\hline Pomalidomide & $22(49)$ \\
\hline Thalidomide & $10(22)$ \\
\hline \multicolumn{2}{|l|}{ Monoclonal Antibodies } \\
\hline Daratumumab & $18(40)$ \\
\hline Elotuzumab & $3(7)$ \\
\hline \multicolumn{2}{|l|}{ SCT } \\
\hline Prior Autologous SCT & $44(98)$ \\
\hline Prior Allogenic SCT & $7(15)$ \\
\hline
\end{tabular}

EMD-extramedullary disease; IMiDs—immunomodulatory drugs; ISS-The Multiple Myeloma International Staging System; LC—light chain; LDH-lactate dehydrogenase; MM-multiple myeloma; NA-not available; PIs-proteasome inhibitors; SCT—-stem cell transplant. 
Table 2. Treatment and response.

\begin{tabular}{|c|c|c|c|c|c|c|}
\hline \multirow{2}{*}{ Pat } & \multirow{2}{*}{ Regimen } & \multirow{2}{*}{ Number of Cycles } & \multirow{2}{*}{ Maximal Dose of Carf } & \multirow{2}{*}{$\begin{array}{l}\text { Dosing of IMiD, Alkylating Agents and } \\
\text { Monoclonal Antibodies }\end{array}$} & \multicolumn{2}{|c|}{ Best Response } \\
\hline & & & & & Serology & EMD \\
\hline 1 & $\mathrm{Kd}$ & 11 & $56 \mathrm{mg} / \mathrm{m}^{2}$ & $\mathrm{~N} / \mathrm{A}$ & PR & PR \\
\hline 2 & $\mathrm{Kd}$ & 1 & $15 \mathrm{mg} / \mathrm{m}^{2}$ & $\mathrm{~N} / \mathrm{A}$ & SD & n.a. \\
\hline 3 & $\mathrm{Kd}$ & 1 & $56 \mathrm{mg} / \mathrm{m}^{2}$ & $\mathrm{~N} / \mathrm{A}$ & PR & SD \\
\hline 4 & $\mathrm{KBd}$ & 1 & $27 \mathrm{mg} / \mathrm{m}^{2}$ & Benda $70 \mathrm{mg} / \mathrm{m}^{2} \mathrm{qw}$ & $\mathrm{N} / \mathrm{A}$ & PD \\
\hline 5 & $\mathrm{KBd}$ & 1 & $27 \mathrm{mg} / \mathrm{m}^{2}$ & Benda $70 \mathrm{mg} / \mathrm{m}^{2} \mathrm{qw}$ & PD & PD \\
\hline 6 & KCyd & 5 & $27 \mathrm{mg} / \mathrm{m}^{2}$ & Cyclo 200 mg qw & PR & $\mathrm{SD}$ \\
\hline 7 & KCyd & 2 & $56 \mathrm{mg} / \mathrm{m}^{2}$ & Cyclo 300 mg qw & PR & n.a. \\
\hline 8 & KCyd & 1 & $27 \mathrm{mg} / \mathrm{m}^{2}$ & Cyclo 750 mg qw & PR & PR \\
\hline 9 & KCyd & 1 & $20 \mathrm{mg} / \mathrm{m}^{2}$ & Cyclo 300 mg qw & PR & mixed response \\
\hline 10 & KCyd & 3 & $27 \mathrm{mg} / \mathrm{m}^{2}$ & Cyclo 300 mg qw & SD & $\mathrm{SD}^{1}$ \\
\hline 11 & $\mathrm{KRd}$ & 11 & $27 \mathrm{mg} / \mathrm{m}^{2}$ & Rev 25 mg qd & PR & PR \\
\hline 12 & $\mathrm{KRd}$ & 7 & $20 \mathrm{mg} / \mathrm{m}^{2}$ & Rev $15 \mathrm{mg}$ qod & VGPR & PR \\
\hline 13 & $\mathrm{KRd}$ & 6 & $36 \mathrm{mg} / \mathrm{m}^{2}$ & Rev 5 mg qd & VGPR & n.a. \\
\hline 14 & $\mathrm{KRd}$ & 2 & $20 \mathrm{mg} / \mathrm{m}^{2}$ & Rev $5 \mathrm{mg}$ qod & SD & n.a. \\
\hline 15 & $\mathrm{KRd}$ & 6 & $27 \mathrm{mg} / \mathrm{m}^{2}$ & Rev 10 mg qd & VGPR & mixed response \\
\hline 16 & $\mathrm{KRd}$ & 3 & $27 \mathrm{mg} / \mathrm{m}^{2}$ & Rev 10 mg qd & $\mathrm{SD}$ & PD \\
\hline 18 & $\mathrm{KRd}$ & 2 & $27 \mathrm{mg} / \mathrm{m}^{2}$ & Rev 25 mg qd & VGPR & n.a. \\
\hline 19 & $\mathrm{KRd}$ & 18 & $27 \mathrm{mg} / \mathrm{m}^{2}$ & Rev 25 mg qd & VGPR & PR \\
\hline 20 & $\mathrm{KRd}$ & 6 & $27 \mathrm{mg} / \mathrm{m}^{2}$ & Rev 25 mg qd & PR & mixed response \\
\hline 21 & $\mathrm{KRd}$ & 3 & $27 \mathrm{mg} / \mathrm{m}^{2}$ & Rev 25 mg qd & PR & PR \\
\hline 22 & $\mathrm{KRd}$ & 5 & $27 \mathrm{mg} / \mathrm{m}^{2}$ & Rev 25 mg qd & VGPR & PR \\
\hline 23 & $\mathrm{KRd}$ & 3 & $27 \mathrm{mg} / \mathrm{m}^{2}$ & Rev $20 \mathrm{mg}$ qd & PR & mixed response \\
\hline 24 & $\mathrm{KRd}$ & 9 & $27 \mathrm{mg} / \mathrm{m}^{2}$ & Rev 25 mg qd & VGPR & n.a. \\
\hline 25 & $\mathrm{KRd}$ & 6 & $27 \mathrm{mg} / \mathrm{m}^{2}$ & Rev 15 mg qd & PR & n.a. \\
\hline 26 & $\mathrm{KRd}$ & 3 & $27 \mathrm{mg} / \mathrm{m}^{2}$ & Rev $10 \mathrm{mg}$ qd & VGPR & SD \\
\hline 27 & $\mathrm{KRd}$ & 1 & $27 \mathrm{mg} / \mathrm{m}^{2}$ & Rev $10 \mathrm{mg}$ qd & PD & n.a. \\
\hline 28 & $\mathrm{KPd}$ & 3 & $27 \mathrm{mg} / \mathrm{m}^{2}$ & Pom $4 \mathrm{mg}$ qd & $\mathrm{SD}$ & mixed response \\
\hline 29 & KTd & 4 & $56 \mathrm{mg} / \mathrm{m}^{2}$ & Thal $50 \mathrm{mg}$ qd & SD & PD \\
\hline 30 & KRCyd & 1 & $20 \mathrm{mg} / \mathrm{m}^{2}$ & Cyclo 300 mg qw, Rev 15 mg qd & PD & PD \\
\hline 31 & KRCyd & 3 & $56 \mathrm{mg} / \mathrm{m}^{2}$ & Cyclo 300 mg qw, Rev 10 mg qd & PD & PD \\
\hline 32 & KRCyd & 3 & $27 \mathrm{mg} / \mathrm{m}^{2}$ & Cyclo $300 \mathrm{mg}$ qw, Rev $10 \mathrm{mg}$ qd & $\mathrm{SD}$ & n.a. \\
\hline
\end{tabular}


Table 2. Cont.

\begin{tabular}{|c|c|c|c|c|c|c|}
\hline \multirow{2}{*}{ Pat } & \multirow{2}{*}{ Regimen } & \multirow{2}{*}{ Number of Cycles } & \multirow{2}{*}{ Maximal Dose of Carf } & \multirow{2}{*}{$\begin{array}{l}\text { Dosing of IMiD, Alkylating Agents and } \\
\text { Monoclonal Antibodies }\end{array}$} & \multicolumn{2}{|c|}{ Best Response } \\
\hline & & & & & Serology & EMD \\
\hline 33 & KTCyd & 4 & $36 \mathrm{mg} / \mathrm{m}^{2}$ & Cyclo $300 \mathrm{mg}$ qw, Thal $100 \mathrm{mg}$ qd & PR & SD \\
\hline 34 & Dara-Kd & 2 & $56 \mathrm{mg} / \mathrm{m}^{2}$ & Dara 16 mg/kg qw & PR & SD \\
\hline 35 & Dara-Kd & 1 & $20 \mathrm{mg} / \mathrm{m}^{2}$ & Dara $16 \mathrm{mg} / \mathrm{kg} \mathrm{qw}$ & PR & SD \\
\hline 36 & Dara-KCyd & 2 & $27 \mathrm{mg} / \mathrm{m}^{2}$ & Dara 16 mg/kg qw, Cyclo 300 mg qw & SD & SD \\
\hline 37 & Dara-KCyd & 2 & $27 \mathrm{mg} / \mathrm{m}^{2}$ & Dara 16 mg/kg qw, Cyclo 200 mg qw & N/A & n.a. \\
\hline 38 & Dara-KCyd & 3 & $15 \mathrm{mg} / \mathrm{m}^{2}$ & Dara 16 mg/kg qw, Cyclo 200 mg qw & PR & PR \\
\hline 39 & Dara-KCyd & 5 & $56 \mathrm{mg} / \mathrm{m}^{2}$ & Dara 16 mg/kg qw, Cyclo 300 mg qw & PR & SD \\
\hline 40 & Dara-KPd & 3 & $27 \mathrm{mg} / \mathrm{m}^{2}$ & Dara 16 mg/kg qw, Pom 3 mg qd & N/A & mixed response \\
\hline 41 & Dara-KPd & 2 & $20 \mathrm{mg} / \mathrm{m}^{2}$ & Dara $16 \mathrm{mg} / \mathrm{kg} \mathrm{qw}$, Pom $2 \mathrm{mg}$ qod & PD & PD \\
\hline 42 & Dara-KPCyd & 1 & $20 \mathrm{mg} / \mathrm{m}^{2}$ & Dara 16 mg/kg qw, Pom 2 mg qd, Cyclo 250 mg qw & PD & n.a. \\
\hline 43 & Dara-KPCyd & 4 & $27 \mathrm{mg} / \mathrm{m}^{2}$ & Dara 16 mg/kg qw, Pom 2 mg qd, Cyclo 200 mg qw & SD & PD \\
\hline 44 & Dara-KPCyd & 1 & $15 \mathrm{mg} / \mathrm{m}^{2}$ & Dara $16 \mathrm{mg} / \mathrm{kg} \mathrm{qw}$, Pom $2 \mathrm{mg}$ qd, Cyclo $200 \mathrm{mg}$ qw & SD & n.a. \\
\hline 45 & Elo-KPd & 1 & $36 \mathrm{mg} / \mathrm{m}^{2}$ & Elo $10 \mathrm{mg} / \mathrm{kg} \mathrm{q} 2 \mathrm{w}$, Pom $2 \mathrm{mg}$ qd & PR & PR \\
\hline
\end{tabular}

Benda—bendamustine; Carf—carfilzomib; Dara—daratumumab; Dara-Kcyd—daratumumab, carfilzomib, cyclophosphamide, dexamethasone; Dara-Kd—daratumumab, carfilzomib, dexamethasone; Dara-KPCyd-daratumumab, carfilzomib, pomalidomide, cyclophosphamide, dexamethasone; Dara-KPd-daratumumab, carfilzomib, pomalidomide, dexamethasone; Elo—elotuzumab; Elo-KPd—elotuzumab, carfilzomib, pomalidomide, dexamethasone; EMDextramedullary disease; ImiD—immunomodulatory drugs; KBd—carfilzomib, bendamustine, dexamethasone; KcyD—carfilzomib, cyclophosphamide, dexamethasone; Kd—carfilzomib, dexamethasone; KPd—carfilzomib, pomalidomide, dexamethasone; KRCyd - carfilzomib, lenalidomide, cyclophosphamide, dexamethasone; KRd—carfilzomib, lenalidomide, dexamethasone; KTCyd—carfilzomib, thalidomide, cyclophosphamide, dexamethasone; KTd—carfilzomib, thalidomide, dexamethasone; N/A—not applicable; n.a.—not available; Pat—Patient; PD—progressive disease; Pom—pomalidomide; PR-partial remission; Rev—lenalidomide; SD-stable disease; Thal—-thalidomide; VGPR—very good partial remission. 
We first analyzed the best serological response in the 42 patients with $\mathrm{M}$ protein and measurable disease. Overall, we observed a serological ORR of $59 \%$ with $19 \%(n=8)$ very good partial remission (VGPR) and $40 \%(n=17)$ partial remission (PR). Ten (24\%) patients achieved stable disease (SD), resulting in a serological CBR of $83 \%$. Seven $(17 \%)$ patients experienced serological progression while being treated with carfilzomib. Imaging follow-up data were available in 33 patients to determine the best response of EMD. No patient with isolated skin lesions, which could have been evaluated without imaging, was included in our study. We observed an extramedullary ORR of $27 \%(n=9)$ with $27 \%$ $(n=9)$ PR. Nine $(27 \%)$ patients had SD at the EMD sites, and, therefore, the CBR in this group was $54 \%$. In addition, extramedullary progression was observed in nine $(27 \%)$ patients. In six $(18 \%)$ patients, a mixed response of EMD lesions was observed, with one EMD lesion progressing under therapy but another lesion responding. Data of response to treatment are summarized in Table 2. Similarly, a high proportion ( $n=15,33 \%)$ of differential response between serological parameters and EMD lesions was observed. Taken together, our data demonstrated an acceptable ORR in this heavily pretreated group of patients, but, notably, no complete remission (CR) could be achieved in our cohort.

$\mathrm{KRd}$ (carfilzomib, lenalidomide, and dexamethasone) was the most frequently administered regimen in our cohort $(n=17)$. In this subgroup, we observed a serological ORR of $76 \%$ with $47 \%$ $(n=8)$ VGPR and $29 \%(n=5)$ PR, and a serological CBR of $88 \%$ with $12 \%(n=2)$ SD. Extramedullary response was available in 11 patients of which $45 \%(n=5)$ and $9 \%(n=1)$ patients achieved PR and SD, respectively. Two (18\%) patients had PD on treatment, and a mixed response was observed in three $(27 \%)$ patients.

\subsection{Survival Analyses}

In our cohort, median PFS and median OS were five (95\% CI, 3.5-6.5) and ten (95\% CI, 7.5-12.5) months, respectively (Figure 1a,b). In univariate analysis, patients suffering from extramedullary plasmacytomas without direct bone contact had a significantly inferior PFS $(p=0.004)$ and OS $(p=0.04)$ compared to those with paraosseous lesions only (Figure 2a,b). Furthermore, elevated LDH indicated a significantly inferior PFS ( $p=0.0008)$, and a trend towards inferior OS $(p=0.06)$ (Figure 2c,d). Another negative prognostic factor was refractory disease to the last line of therapy with poorer PFS $(p=0.0005)$ and OS $(p<0.0001)$ compared to those with a progression from remission (Figure 2e,f). Furthermore, the PFS of patients who were treated with $\geq 4$ prior lines of therapy was significantly shorter when compared with those who received less than four prior therapy lines $(p=0.02$, Figure $2 \mathrm{~g}$ ). We also observed that patients who received $\geq 4$ prior therapy lines had a trend towards an inferior OS compared to those treated with less than four prior lines of therapy ( $p=0.08$, Figure $2 \mathrm{~h}$ ). However, high-risk cytogenetics showed no significant negative prognostic value in our cohort (not shown in Figure 2). Due to the limited number of patients in our study, we did not perform a multivariate analysis.
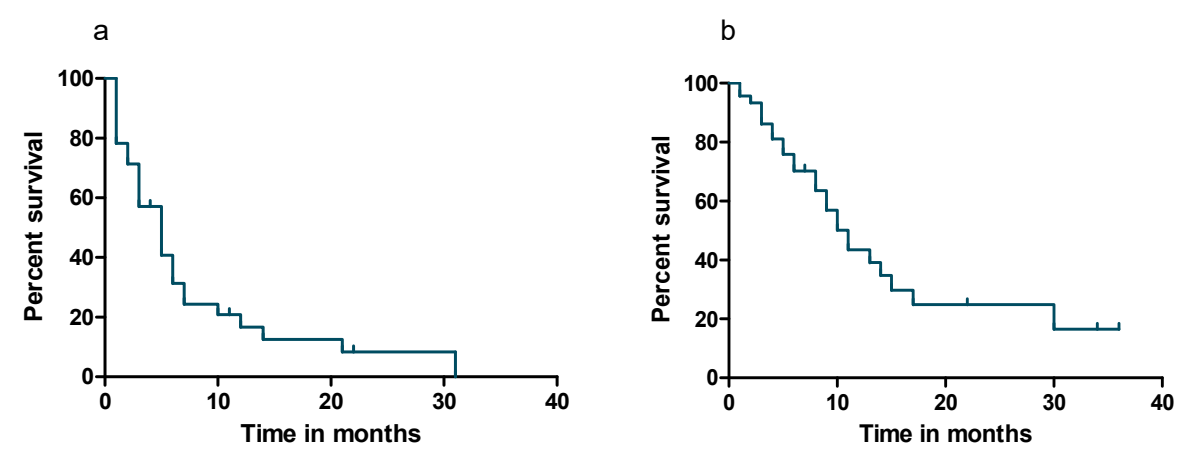

Figure 1. Progression-free survival (PFS) (a) $(n=45)$ and overall survival (OS) (b) $(n=45)$ of patients. 

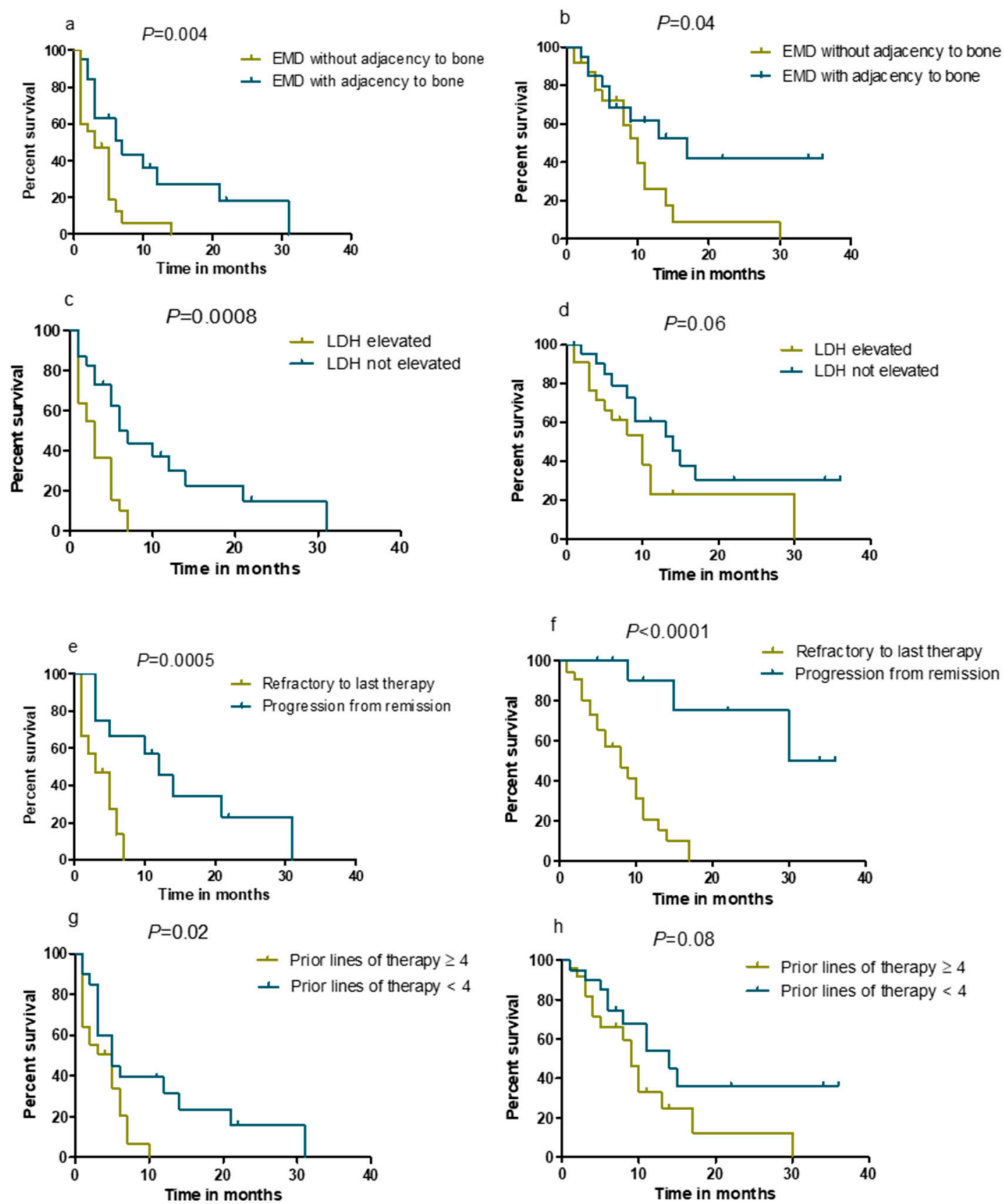

Figure 2. Progression-free survival (PFS) (a) and overall survival (OS) (b) in patients with extramedullary disease (EMD) adjacent to bone or not (EMD with adjacency to bone, $n=20$; EMD without adjacency to bone, $n=25)$. PFS (c) and OS (d) in patients with normal vs. elevated lactate dehydrogenase (LDH) level (LDH $<250 \mathrm{IU} / 1, n=23 ; \mathrm{LDH} \geq 250 \mathrm{IU} / 1, n=22)$. PFS (e) and OS (f) in patients who were refractory to the last therapy line $(n=33)$ vs. who were not $(n=12)$. PFS $(\mathbf{g})$ and OS $(\mathbf{h})$ of patients with $\geq 4$ prior therapy lines $(n=25)$ and $<4$ prior therapy lines $(n=20)$.

\subsection{Adverse Events (AEs)}

Hematological AEs were the most common AEs during the treatment. We observed anemia, leukopenia, neutropenia, and thrombocytopenia grade $\geq 3$ in $25(56 \%), 24(53 \%), 13(29 \%)$, and $22(49 \%)$ patients, respectively. When necessary, granulocyte colony-stimulating factor (G-CSF) and red cell or platelet concentrates were administered according to the current guidelines [33,34]. Among the non-hematological AEs, pneumonia $(n=6,13 \%)$ was the most common AE grade $\geq 3$. Additionally, 
five $(11 \%)$ patients developed heart failure grade $\geq 3$, possibly related to carfilzomib. In one of the five patients, the treatment had to be withdrawn after one cycle, and in the other four patients, treatment was continued after recovery of cardiac function. In total, two $(4 \%)$ patients died due to pneumonia during the second and fourth cycles of treatment, respectively. One of both patients had a non-secretory MM with EMD and achieved an extramedullary mixed response after three cycles of Dara-KPd (daratumumab, carfilzomib, pomalidomide, and dexamethasone). In the other patient, PD was observed after one cycle of KRd. AEs are summarized in Table 3.

Table 3. Adverse events during therapy.

\begin{tabular}{cccc}
\hline Adverse Events & Any Grade $\geq \mathbf{2}$ & Grade $\mathbf{3}$ & Grade $\mathbf{4}$ \\
\hline Hematological Events, $\boldsymbol{n} \mathbf{( \% )}$ & $37(82)$ & $25(56)$ & \\
Anemia & $32(71)$ & $19(42)$ & $5(11)$ \\
White Blood Cell Decreased & $30(67)$ & $7(16)$ & $6(13)$ \\
Neutrophil Count Decreased & $29(64)$ & $9(20)$ & $13(29)$ \\
Platelet Count Decreased & $1(2)$ & & $1(2)$ \\
Febrile Neutropenia & & & \\
Non-Hematological Events, $\boldsymbol{n} \mathbf{( \% )}$ & $6(13)$ & $4(9)$ & $2(4)$ \\
Pneumonia & $6(13)$ & $5(11)$ & \\
Heart Failure & $4(9)$ & $4(9)$ & \\
Influenza & $3(7)$ & $3(7)$ & \\
Upper Respiratory Infection & $2(4)$ & $1(2)$ & \\
Liver Enzyme Increased & $2(4)$ & $2(4)$ & \\
Urinary Tract Infection & $1(2)$ & $1(2)$ & \\
Cytokine Release Syndrome & $1(2)$ & $1(2)$ & \\
Gastrointestinal Infection & $1(2)$ & $1(2)$ & \\
Catheter Related Infection & $1(2)$ & $1(2)$ & \\
Peripheral Polyneuropathy & $1(2)$ & $1(2)$ & \\
Convulsion & $1(2)$ & $1(2)$ & \\
Renal Failure & $1(2)$ & $1(2)$ & \\
Oral Hemorrhage & $1(2)$ & $1(2)$ & \\
Bacterial Meningitis & $1(2)$ & $1(2)$ & \\
Skin Infection & $1(2)$ & $1(2)$ & \\
Sinusitis & $1(2)$ & & \\
Atrial Fibrillation & $2(4)$ & & \\
Thromboembolic Events & $2(4)$ & & \\
Death & & & \\
& & & \\
\hline
\end{tabular}

\section{Discussion}

The optimal management of extramedullary RRMM remains largely unclear. In the current study, we retrospectively analyzed the role of carfilzomib in the management of EMD. In total, we observed a serological ORR of $59 \%$ and a serological CBR of $83 \%$. With regard to extramedullary response, ORR and CBR were $27 \%$ and $54 \%$, respectively. To the best of our knowledge, there is no prospective study specifically investigating carfilzomib based treatment in EMD. Carfilzomib based treatments had shown EMD efficacy in case reports [35-37]. In a recent retrospective observational study, Muchtar et al. reported on a subgroup of patients with extramedullary RRMM who achieved a lower ORR (40\%) and CBR $(43.3 \%)$ when compared with patients without $\mathrm{EMD}(\mathrm{ORR}=49 \%, \mathrm{CBR}=63.5 \%)$ [38].

Of note, serological response differed from the extramedullary response in $33 \%$ of patients of our cohort, and six patients achieved an extramedullary mixed response. Indeed, intra-tumor genomic heterogeneity with advanced clones located to EMD might explain the lower response rates of these lesions compared to intramedullary disease [39,40]. Our study highlights the need for medical imaging in the follow-up of patients with EMD [41]. In our current study, the median PFS was five $(95 \%$ CI, 3.5-6.5) months, and the median OS was ten (95\% CI, 7.5-12.5) months. Comparably, Muchtar et al. reported a median duration of response of 3.9 months in patients with extramedullary RRMM, 
who were treated with carfilzomib containing regimens [38]. In a previous study of our institution investigating patients with EMD prior to the carfilzomib era, patients were treated with intensive chemotherapy, such as VDT-PACE, VRD-ICE, RAD, VCDT, and autologous or allogeneic SCT, and we observed a median PFS and OS of two (95\% CI, 0.08-3.92) and seven (95\% CI, 3.56-10.43) months, respectively [11]. Additionally, Rasche et al. reported a median PFS of four months in patients with extramedullary RRMM treated with DexaBEAM [17]. At our institution, the novel CXCR4-directed endoradiotherapy (ERT) has shown promising efficacy (ORR 75\%) but no favorable survival outcome (median PFS 54 days, range 13-175 days and median OS 223 days, range 13-313 days) in extramedullary relapsed MM [42].

Our results suggest that patients with extramedullary plasmacytomas not adjacent to bone had a significantly inferior PFS and OS compared with those with paraosseous EMD. Similarly, Beksac et al. also reported that paraosseous lesions indicated a significantly superior PFS and OS when compared to extramedullary plasmacytomas without bone contact [43]. Furthermore, we observed that patients who were refractory to the last line of therapy represented a negative prognostic factor for PFS and OS. Our findings suggested that carfilzomib-containing treatment had only limited efficacy in this patient group.

Overall, five (11\%) patients developed acute heart failure grade $\geq 3$, and two (4\%) patients died due to pneumonia during treatment. Hematological AEs including anemia, leukopenia, neutropenia, and thrombocytopenia grade $\geq 3$ were observed in $25(56 \%), 24(53 \%), 13(29 \%)$, and $22(49 \%)$ patients, respectively. Due to the regular use of G-SCF and transfusion of blood products, these hematological AEs were well manageable. Generally, the rates of AEs grade $\geq 3$ and the mortality during treatment were comparable to previous clinical studies investigating carfilzomib based therapy in RRMM [44-46].

There were several limitations to our current study. First, this is a retrospective analysis based on a relatively small number of patients who received heterogeneous carfilzomib containing treatment regimens. Second, the missing values might be a further limitation of our study.

\section{Conclusions}

In conclusion, compared to previous studies prior to the carfilzomib era, carfilzomib-based treatment strategies have shown similar ORR but improved survival outcome (PFS and OS) in patients with extramedullary RRMM. However, EMD still heralds poor prognosis, especially in patients being refractory to the last therapy line. In addition, due to the high proportion of discrepant response between serological parameters and EMD lesion, evaluation of extramedullary response using imaging should be performed in these patients.

Author Contributions: Conceptualization, X.Z., H.E., K.M.K., and L.R.; Data curation, X.Z.; Formal analysis, X.Z.; Funding acquisition, H.E., K.M.K., and L.R.; Investigation, X.Z., H.E., K.M.K., and L.R.; Methodology, X.Z., H.E., K.M.K., and L.R.; Project administration, X.Z. and L.R.; Resources, X.Z., P.F., H.E., K.M.K., and L.R.; Software, X.Z.; Supervision, X.Z., H.E., and L.R.; Validation, X.Z. and H.E.; Visualization, X.Z.; Writing—original draft, X.Z.; Writing-review and editing, P.F., K.N., K.M., J.M., D.B., S.K., M.J.S., F.K., S.D., H.E., K.M.K., and L.R. All authors have read and agreed to the published version of the manuscript.

Funding: This research received no external funding.

Acknowledgments: Leo Rasche was supported by the IZKF Würzburg (Z-3R/2) and by the German Cancer Aid via the MSNZ program. Martin Kortüm was supported by the the German Cancer Aid via the MSNZ program and the Bayerisch-Tschechische Hochschulagentur (BTHA).

Conflicts of Interest: The authors declare no conflict of interest.

\section{References}

1. Bladé, J.; De Larrea, C.F.; Rosiñol, L.; Cibeira, M.T.; Jiménez, R.; Powles, R. Soft-Tissue Plasmacytomas in Multiple Myeloma: Incidence, Mechanisms of Extramedullary Spread, and Treatment Approach. J. Clin. Oncol. 2011, 29, 3805-3812. [CrossRef] 
2. Sevcikova, S.; Minarik, J.; Stork, M.; Jelinek, T.; Pour, L.; Hajek, R. Extramedullary disease in multiple myeloma-Controversies and future directions. Blood Rev. 2019, 36, 32-39. [CrossRef] [PubMed]

3. Weinstock, M.; Ghobrial, I.M. Extramedullary multiple myeloma. Leuk. Lymphoma 2012, 54, $1135-1141$. [CrossRef]

4. Weinstock, M.; Aljawai, Y.; Morgan, E.A.; Laubach, J.; Gannon, M.; Roccaro, A.; Varga, C.; Mitsiades, C.S.; Paba-Prada, C.; Schlossman, R.; et al. Incidence and clinical features of extramedullary multiple myeloma in patients who underwent stem cell transplantation. Br. J. Haematol. 2015, 169, 851-858. [CrossRef]

5. Hedvat, C.; Comenzo, R.L.; Teruya-Feldstein, J.; Olshen, A.B.; Ely, S.A.; Osman, K.; Zhang, Y.; Kalakonda, N.; Nimer, S.D. Insights into extramedullary tumour cell growth revealed by expression profiling of human plasmacytomas and multiple myeloma. Br. J. Haematol. 2003, 122, 728-744. [CrossRef] [PubMed]

6. Azab, A.K.; Hu, J.; Quang, P.; Azab, F.; Pitsillides, C.; Awwad, R.; Thompson, B.; Maiso, P.; Sun, J.D.; Hart, C.; et al. Hypoxia promotes dissemination of multiple myeloma through acquisition of epithelial to mesenchymal transition-like features. Blood 2012, 119, 5782-5794. [CrossRef]

7. Roccaro, A.; Mishima, Y.; Sacco, A.; Moschetta, M.; Tai, Y.-T.; Shi, J.; Zhang, Y.; Reagan, M.R.; Huynh, D.; Kawano, Y.; et al. CXCR4 regulates extra-medullary myeloma through epithelial-mesenchymal transition-like transcriptional activation. Cell Rep. 2015, 12, 622-635. [CrossRef] [PubMed]

8. Bešše, L.; Sedlař́́ková, L.; Greslikova, H.; Kupska, R.; Almáši, M.; Penka, M.; Jelinek, T.; Pour, L.; Adam, Z.; Kuglik, P.; et al. Cytogenetics in multiple myeloma patients progressing into extramedullary disease. Eur. J. Haematol. 2015, 97, 93-100. [CrossRef]

9. Deng, S.; Xu, Y.; An, G.; Sui, W.; Zou, D.; Zhao, Y.; Qi, J.; Li, F.; Hao, M.; Qiu, L. Features of Extramedullary Disease of Multiple Myeloma: High Frequency of P53 Deletion and Poor Survival: A Retrospective Single-Center Study of 834 Cases. Clin. Lymphoma Myeloma Leuk. 2015, 15, 286-291. [CrossRef] [PubMed]

10. Billecke, L.; Penas, E.M.M.; May, A.M.; Engelhardt, M.; Nagler, A.; Leiba, M.; Schiby, G.; Kröger, N.; Zustin, J.; Marx, A.H.; et al. Cytogenetics of extramedullary manifestations in multiple myeloma. Br. J. Haematol. 2013, 161, 87-94. [CrossRef]

11. Rasche, L.; Bernard, C.; Topp, M.S.; Kapp, M.; Duell, J.; Wesemeier, C.; Haralambieva, E.; Maeder, U.; Einsele, H.; Knop, S. Features of extramedullary myeloma relapse: High proliferation, minimal marrow involvement, adverse cytogenetics: A retrospective single-center study of 24 cases. Ann. Hematol. 2012, 91, 1031-1037. [CrossRef] [PubMed]

12. Usmani, S.Z.; Heuck, C.; Mitchell, A.; Szymonifka, J.; Nair, B.; Hoering, A.; Alsayed, Y.; Waheed, S.; Haider, S.; Restrepo, A.; et al. Extramedullary disease portends poor prognosis in multiple myeloma and is over-represented in high-risk disease even in the era of novel agents. Haematologica 2012, 97, 1761-1767. [CrossRef] [PubMed]

13. Varettoni, M.; Corso, A.; Pica, G.; Mangiacavalli, S.; Pascutto, C.; Lazzarino, M. Incidence, presenting features and outcome of extramedullary disease in multiple myeloma: A longitudinal study on 1003 consecutive patients. Ann. Oncol. 2010, 21, 325-330. [CrossRef] [PubMed]

14. Pour, L.; Ševčíková, S.; Greslikova, H.; Kupska, R.; Majkova, P.; Zahradova, L.; Sandecka, V.; Adam, Z.; Krejci, M.; Kuglik, P.; et al. Soft-tissue extramedullary multiple myeloma prognosis is significantly worse in comparison to bone-related extramedullary relapse. Haematol. 2013, 99, 360-364. [CrossRef] [PubMed]

15. Short, K.D.; Rajkumar, S.V.; Larson, D.; Buadi, F.; Hayman, S.; Dispenzieri, A.; Gertz, M.; Kumar, S.; Mikhael, J.; Roy, V.; et al. Incidence of extramedullary disease in patients with multiple myeloma in the era of novel therapy, and the activity of pomalidomide on extramedullary myeloma. Leukemia 2011, 25, 906-908. [CrossRef] [PubMed]

16. Mangiacavalli, S.; Pompa, A.; Ferretti, V.; Klersy, C.; Cocito, F.; Varettoni, M.; Cartia, C.S.; Cazzola, M.; Corso, A. The possible role of burden of therapy on the risk of myeloma extramedullary spread. Ann. Hematol. 2016, 96, 73-80. [CrossRef]

17. Rasche, L.; Strifler, S.; Duell, J.; Rosenwald, A.; Buck, A.; Maeder, U.; Einsele, H.; Knop, S. The lymphoma-like polychemotherapy regimen "Dexa-BEAM" in advanced and extramedullary multiple myeloma. Ann. Hematol. 2014, 93, 1207-1214. [CrossRef]

18. Lakshman, A.; Singh, P.P.; Rajkumar, S.V.; Dispenzieri, A.; Lacy, M.Q.; Gertz, M.A.; Buadi, F.K.; Dingli, D.; Hwa, Y.L.; Fonder, A.L.; et al. Efficacy of VDT PACE-like regimens in treatment of relapsed/refractory multiple myeloma. Am. J. Hematol. 2017, 93, 179-186. [CrossRef] 
19. Rasche, L.; Röllig, C.; Stuhler, G.; Danhof, S.; Mielke, S.; Grigoleit, G.U.; Dissen, L.; Schemmel, L.; Middeke, J.M.; Rücker, V.; et al. Allogeneic Hematopoietic Cell Transplantation in Multiple Myeloma: Focus on Longitudinal Assessment of Donor Chimerism, Extramedullary Disease, and High-Risk Cytogenetic Features. Boil. Blood Marrow Transplant. 2016, 22, 1988-1996. [CrossRef]

20. Lonial, S.; Weiss, B.M.; Usmani, S.Z.; Singhal, S.; Chari, A.; Bahlis, N.J.; Belch, A.; Krishnan, A.; Vescio, R.A.; Mateos, M.-V.; et al. Daratumumab monotherapy in patients with treatment-refractory multiple myeloma (SIRIUS): An open-label, randomised, phase 2 trial. Lancet 2016, 387, 1551-1560. [CrossRef]

21. Groen, K.; Van De Donk, N.W.C.J.; Stege, C.; Zweegman, S.; Nijhof, I. Carfilzomib for relapsed and refractory multiple myeloma. Cancer Manag. Res. 2019, 11, 2663-2675. [CrossRef] [PubMed]

22. Dimopoulos, M.A.; Goldschmidt, H.; Niesvizky, R.; Joshua, D.; Chng, W.-J.; Oriol, A.; Orlowski, R.Z.; Ludwig, H.; Facon, T.; Hajek, R.; et al. Carfilzomib or bortezomib in relapsed or refractory multiple myeloma (ENDEAVOR): An interim overall survival analysis of an open-label, randomised, phase 3 trial. Lancet Oncol. 2017, 18, 1327-1337. [CrossRef]

23. Chng, W.-J.; Goldschmidt, H.; Dimopoulos, M.A.; Moreau, P.; Joshua, D.; Palumbo, A.; Facon, T.; Ludwig, H.; Pour, L.; Niesvizky, R.; et al. Carfilzomib-dexamethasone vs bortezomib-dexamethasone in relapsed or refractory multiple myeloma by cytogenetic risk in the phase 3 study ENDEAVOR. Leukemia 2017, 31, 1368-1374. [CrossRef]

24. Stewart, A.K.; Rajkumar, S.V.; Dimopoulos, M.A.; Masszi, T.; Spicka, I.; Oriol, A.; Hajek, R.; Rosiñol, L.; Siegel, D.S.; Mihaylov, G.G.; et al. Carfilzomib, Lenalidomide, and Dexamethasone for Relapsed Multiple Myeloma. N. Engl. J. Med. 2015, 372, 142-152. [CrossRef] [PubMed]

25. Chari, A.; Lopez, J.M.; Mateos, M.-V.; Bladé, J.; Benboubker, L.; Oriol, A.; Arnulf, B.; Rodriguez-Otero, P.; Pineiro, L.; Jakubowiak, A.; et al. Daratumumab plus carfilzomib and dexamethasone in patients with relapsed or refractory multiple myeloma. Blood 2019, 134, 421-431. [CrossRef]

26. Shah, J.J.; Stadtmauer, E.A.; Abonour, R.; Cohen, A.D.; Bensinger, W.I.; Gasparetto, C.; Kaufman, J.L.; Lentzsch, S.; Vogl, D.T.; Gomes, C.L.; et al. Carfilzomib, pomalidomide, and dexamethasone for relapsed or refractory myeloma. Blood 2015, 126, 2284-2290. [CrossRef]

27. Rajkumar, S.V.; Harousseau, J.L.; Durie, B.; Anderson, K.C.; Dimopoulos, M.; Kyle, R.; Blade, J.; Richardson, P.; Orlowski, R.; Siegel, D.; et al. Consensus recommendations for the uniform reporting of clinical trials: Report of the International Myeloma Workshop Consensus Panel 1. Blood 2011, 117, 4691-4695. [CrossRef]

28. Fonseca, R.; Blood, E.; Rué, M.; Harrington, D.; Oken, M.; Kyle, R.A.; Dewald, G.W.; Van Ness, B.; Van Wier, S.A.; Henderson, K.J.; et al. Clinical and biologic implications of recurrent genomic aberrations in myeloma. Blood 2003, 101, 4569-4575. [CrossRef]

29. Mikhael, J.; Dingli, D.; Roy, V.; Reeder, C.B.; Buadi, F.K.; Hayman, S.R.; Dispenzieri, A.; Fonseca, R.; Sher, T.; Kyle, R.A.; et al. Management of Newly Diagnosed Symptomatic Multiple Myeloma: Updated Mayo Stratification of Myeloma and Risk-Adapted Therapy (mSMART) Consensus Guidelines 2013. Mayo Clin. Proc. 2013, 88, 360-376. [CrossRef]

30. Chng, W.J.; Dispenzieri, A.; Chim, C.-S.; Fonseca, R.; Goldschmidt, H.; Lentzsch, S.; Munshi, N.; Palumbo, A.; San-Miguel, J.F.; Sonneveld, P.; et al. IMWG consensus on risk stratification in multiple myeloma. Leukemia 2013, 28, 269-277. [CrossRef]

31. Durie, B.G.M.; Harousseau, J.-L.; Miguel, J.S.; Blade, J.; Barlogie, B.; Anderson, K.; Gertz, M.; Dimopoulos, M.; Westin, J.; Sonneveld, P.; et al. International uniform response criteria for multiple myeloma. Leukemia 2006, 20, 1467-1473. [CrossRef] [PubMed]

32. Kumar, S.K.; Paiva, B.D.L.; Anderson, K.C.; Durie, B.; Landgren, O.; Moreau, P.; Munshi, N.C.; Lonial, S.; Bladé, J.; Mateos, M.-V.; et al. International Myeloma Working Group consensus criteria for response and minimal residual disease assessment in multiple myeloma. Lancet Oncol. 2016, 17, e328-e346. [CrossRef]

33. Smith, T.; Bohlke, K.; Lyman, G.H.; Carson, K.R.; Crawford, J.; Cross, S.J.; Goldberg, J.M.; Khatcheressian, J.L.; Leighl, N.B.; Perkins, C.L.; et al. Recommendations for the Use of WBC Growth Factors: American Society of Clinical Oncology Clinical Practice Guideline Update. J. Clin. Oncol. 2015, 33, 3199-3212. [CrossRef] [PubMed]

34. Lancet Haematol. Updates on blood transfusion guidelines. Lancet Haematol. 2016, 3, e547. [CrossRef]

35. Mele, G.; Pastore, D. Efficacy of Carfilzomib, Lenalidomide, and Dexamethasone for Extramedullary Intracranial Localization of Multiple Myeloma. Case Rep. Hematol. 2018, 2018, 1-3. [CrossRef] 
36. Español, I.; Romera, M.; Gutiérrez-Meca, M.D.; García, M.D.C.; Tejedor, A.; Martínez, A.; Ibáñez, J.; De Arriba, F.; Minguela, A.; Iturbe, T.; et al. Carfilzomib and dexamethasone for extramedullary myeloma with pleuropericardial involvement. Clin. Case Rep. 2017, 5, 1258-1260. [CrossRef]

37. Parnell, K.; Ahmed, M.; Smalligan, R.D.; Nadesan, S. Extramedullary plasmacytoma mimicking colon carcinoma: An unusual presentation and review of the literature. BMJ Case Rep. 2015, 2015. [CrossRef]

38. Muchtar, E.; Gatt, M.E.; Rouvio, O.; Ganzel, C.; Chubar, E.; Suriu, C.; Tadmor, T.; Shevetz, O.; Lavi, N.; Shochat, T.; et al. Efficacy and safety of salvage therapy using Carfilzomib for relapsed or refractory multiple myeloma patients: A multicentre retrospective observational study. Br. J. Haematol. 2015, 172, 89-96. [CrossRef]

39. Rasche, L.; Chavan, S.S.; Stephens, O.W.; Patel, P.H.; Tytarenko, R.; Ashby, C.; Bauer, M.A.; Stein, C.; Deshpande, S.; Wardell, C.; et al. Spatial genomic heterogeneity in multiple myeloma revealed by multi-region sequencing. Nat. Commun. 2017, 8, 268. [CrossRef]

40. López-Anglada, L.; Gutiérrez, N.C.; García, J.L.; Mateos, M.V.; Flores, T.; San-Miguel, J.F. P53deletion may drive the clinical evolution and treatment response in multiple myeloma. Eur. J. Haematol. 2010, 84, 359-361. [CrossRef]

41. Hillengass, J.; Usmani, S.; Rajkumar, S.V.; Durie, B.G.M.; Mateos, M.-V.; Lonial, S.; Joao, C.; Anderson, K.C.; García-Sanz, R.; Riva, E.; et al. International myeloma working group consensus recommendations on imaging in monoclonal plasma cell disorders. Lancet Oncol. 2019, 20, e302-e312. [CrossRef]

42. Lapa, C.; Herrmann, K.; Schirbel, A.; Hänscheid, H.; Lückerath, K.; Schottelius, M.; Kircher, M.; Werner, R.A.; Schreder, M.; Samnick, S.; et al. CXCR4-directed endoradiotherapy induces high response rates in extramedullary relapsed Multiple Myeloma. Theranostics 2017, 7, 1589-1597. [CrossRef] [PubMed]

43. Beksac, M.; Seval, G.C.; Kanellias, N.; Coriu, D.; Rosiñol, L.; Ozet, G.; Goranova-Marinova, V.; Unal, A.; Bila, J.; Ozsan, H.; et al. A real world multicenter retrospective study on extramedullary disease from Balkan Myeloma Study Group and Barcelona University: Analysis of parameters that improve outcome. Haematologica 2019, 105, 201-208. [CrossRef]

44. Dimopoulos, M.A.; Moreau, P.; Iida, S.; Huang, S.-Y.; Takezako, N.; Chng, W.J.; Zahlten-Kumeli, A.; Sersch, M.A.; Li, J.; Huang, M.; et al. Outcomes for Asian patients with multiple myeloma receiving once- or twice-weekly carfilzomib-based therapy: A subgroup analysis of the randomized phase 3 ENDEAVOR and A.R.R.O.W. Trials. Int. J. Hematol. 2019, 110, 466-473. [CrossRef] [PubMed]

45. Moreau, P.; Mateos, M.-V.; Berenson, J.R.; Weisel, K.; Lazzaro, A.; Song, K.; Dimopoulos, M.A.; Huang, M.; Zahlten-Kumeli, A.; Stewart, A.K. Once weekly versus twice weekly carfilzomib dosing in patients with relapsed and refractory multiple myeloma (A.R.R.O.W.): Interim analysis results of a randomised, phase 3 study. Lancet Oncol. 2018, 19, 953-964. [CrossRef]

46. Mateos, M.-V.; Goldschmidt, H.; San-Miguel, J.F.; Mikhael, J.; DeCosta, L.; Zhou, L.; Obreja, M.; Blaedel, J.; Szabo, Z.; Leleu, X. Carfilzomib in relapsed or refractory multiple myeloma patients with early or late relapse following prior therapy: A subgroup analysis of the randomized phase 3 ASPIRE and ENDEAVOR trials. Hematol. Oncol. 2018, 36, 463-470. [CrossRef]

(C) 2020 by the authors. Licensee MDPI, Basel, Switzerland. This article is an open access article distributed under the terms and conditions of the Creative Commons Attribution (CC BY) license (http://creativecommons.org/licenses/by/4.0/). 